\title{
Comparative Studies on Phytochemical Screening and in Vitro Antioxidant Activities of Aqueous Extracts of Anacardium Occidentale Leaves and Nuts
}

\author{
Philip O. Amira, Adebayo S. Daramola, Chikwado E. Muoghalu and Oluwamodupe B. Ojo
}

\section{ABSTRACT}

Phytochemicals are plant-derived chemicals, which are beneficial to human health and disease. They are naturally occurring in the medicinal plants, vegetables, leaves and roots that have defense mechanism and protect from various diseases as well inhibit, or delay the oxidation of other molecules by inhibiting the initiation or propagation of oxidizing chain reaction. Cashew (Anacardium occidentale) is one of the most important nut-bearing trees. Therefore, comparative studies on the phytochemical screening and in vitro antioxidant activities on aqueous extracts of leaves and nuts of Anacardium occidentale were investigated to assess their antioxidant properties in different antioxidant property determination assays. Aqueous extracts of the Anacardium occidentale leaves and nuts revealed the presence of resin, flavonoids, phenols, carbohydrates, alkaloids and terpenoids. In addition, the aqueous leaf extract of the plant contained tannins, saponins, phlobatanins and steroids. The IC50 $(\mu \mathrm{g} / \mathrm{ml})$ values of the leaves' extract were $36.77 \pm 1.11,1.71 \pm 0.10,1.01 \pm 0.07,0.11 \pm 0.002$ and $0.99 \pm 0.22$ for total antioxidant capacity (AAE), ferric reducing antioxidant activity (AAE), diphenyl picryl hydrazyl (DPPH) assay, nitric oxide (NO) scavenging activity and metal chelating activity respectively. On the other hand, the IC50 $(\mu \mathrm{g} / \mathrm{ml})$ values of the nuts' extract were $34.85 \pm 0.27,1.37 \pm$ $0.02,4.65 \pm 0.19,8.65 \pm 0.09$ and $3.54 \pm 0.05$ for total antioxidant capacity (AAE), ferric reducing antioxidant activity (AAE), diphenyl picryl hydrazyl (DPPH) assay, nitric oxide (NO) scavenging activity and metal chelating activity respectively. Consequently, even though both extracts exhibited remarkable in vitro antioxidant properties, the leaf extract seemed to have better performance with respect to the parameters investigated.

Keywords: Phytochemical, Antioxidant, in vivo, Anacardium occidentale, medicinal.

\section{INTRODUCTION}

Phytochemicals can be defined as plant-derived chemicals, which are beneficial to human health and disease. In plants, phytochemicals repel harmful and attract beneficial organisms, serve as photo-protectants and exhibit appropriate response to environmental changes [1]. Phytochemicals are naturally occurring in the medicinal plants, vegetables, leaves and roots that have defense mechanism and protect from various diseases. In fact, phytochemicals (or antioxidants) such as nitrogen compounds (alkaloids, chlorophyll derivatives, amino acids and amines), phenolic compounds (tocopherols, flavonoids and phenolic acids), carotenoids and ascorbic acid [14], [25] inhibit, or delay the oxidation of other molecules by inhibiting the initiation or propagation of oxidizing chain reaction.
Published Online: July 15, 2020

ISSN: 2684-5199

DOI : $10.24018 /$ ejbio.2020.1.4.49

Philip O. Amira

The Federal Polytechnic, Nigeria. Adebayo S. Daramola*

The Federal Polytechnic, Nigeria.

(e-mail:success4daramola@ ${ }^{@}$ gmail.com)

Chikwado E. Muoghalu

The Federal Polytechnic, Nigeria.

Oluwamodupe B. Ojo

The Federal Polytechnic, Nigeria.

*Corresponding Author
There is currently considerable interest in the antioxidant capacity of the human diet for its potential to prevent chronic diseases such as cancer, cardiovascular disease, diabetes and Alzheimer's disease [9], [18], [23], [27]. Epidemiological studies have shown that there is an inverse association between diet rich in fruits, vegetables, grains and nuts and chronic diseases [2], [4], [22]. Antioxidant compounds present in foods may help to protect cellular systems in the human body from oxidative damage and thus lower the risk of chronic diseases [20].

Reactive oxygen species (ROS) are constantly formed in the human body by normal metabolic action and these exert oxidative damaging effects by reacting with nearly every molecule found in living cells including nucleic acids, proteins, lipids or DNA and may involve in several chronic and degenerative diseases including gastritis, reperfusion injury of many tissues, atherosclerosis, ischemic heart disease, ageing, diabetes mellitus, cancer, 
immunosuppression, neurodegenerative diseases and others [28], [32] if excess ROS and free radicals are not eliminated by endogenous ntioxidant system.

An antioxidant is a molecule capable of slowing or preventing the oxidation of other molecules. Synthetic antioxidants such as butylated hydroxytoluene (BHT), butylated hydroxyanisole (BHA), propylgallate (PG) and tertiary butyl-hydroquinone (TBHQ) are known to ameliorate oxidative damages but they have been restricted due to the carcinogenic and harmful effect on the lungs and liver [13]. Therefore, investigations of antioxidants are focused on naturally occurring substances, especially phytochemicals. Antioxidant compounds in food play an important role as a health protecting factor. Plant-sourced food antioxidants like vitamin $\mathrm{C}$, vitamin $\mathrm{E}$, carotenes, phenolic acids, phytate and phytoestrogens have been recognized as having the potential to reduce disease risk. Most of the antioxidant compounds in a typical diet are derived from plant sources and belong to various classes of compounds with a wide variety of physical and chemical properties. The main characteristic of an antioxidant is its ability to trap free radicals [34]. Anacardium occidentale is a medicinal plant and its leaf is reputed in folklore system of medicine in tropical countries, and of which the pharmacological activities have been scientifically demonstrated. Cashew (Anacardium occidentale) is one of the most important tree nuts and rank third in international trade after hazelnuts and almonds. Phenolic substances have been proposed as important contributors to the total antioxidant capacity (TAC) of tree nuts [8], [16]. Much attention has recently been paid to the possible health benefits of dietary phenolic phytochemicals that exhibit antioxidative, antibacterial, antiviral, anticarcinogenic, antiinflammatory and vasodilatory actions[7], [11]. The importance and health benefit of fruit and vegetable consumption in prevention of chronic diseases have been well documented. The attention paid to health benefits of tree nut consumption has been little compared to that for fruits and vegetables. There had been investigations on the antioxidant capacity and phenolic contents of processed cashew nuts, cashew apple and cashew leaf extracts. However, a very few researches have investigated the phytochemical contents and antioxidant activities of different tissues of raw cashew leaves and nuts. Consequently, comparative studies on the phytochemical screening and in vitro activity on aqueous extracts of leaf and nuts of Anacardium occidentale were investigated to assess their antioxidant properties in different antioxidant property determination assays including Total antioxidant capacity (TAC), Ferric Reducing Antioxidant Property (FRAP), DPPH radical scavenging, Total Phenol, Total Flavonoids, NO scavenging activity and Metal chelating activity were studied in this report. Ascorbic acid, Garlic acid and EDTA were used as standards.

\section{MATERIALS AND METHODS}

\section{A. Collection of plant materials}

The leaves and seeds of Anacardium occidentale were collected from Aba-Erinfun, Ado Local Government Area in
Ado-Ekiti, Ekiti State, Nigeria. Identification of the sample took place at the Biochemistry Unit, Department of Science Technology, Federal Polytechnic Ado-Ekiti, Ekiti State, Nigeria.

\section{B. Preparation of extracts}

The fresh young leaves were air-dried to obtain dry sample which was later ground first with mortar and pestle and thereafter, with a milling machine to obtain a fine powder. On the other hand, the fresh seeds were air dried first and roasted, the outer covering removed in order to obtain the nuts. These nuts were again air-dried, ground with a milling machine to obtain a fine powder. The ground powder in each case was dissolved in distilled water in a ratio of 1:20 (100 $\mathrm{g}$ in $2 \mathrm{~L}$ distilled water). This extraction took place in an extractor for 72 hours with regular stirring. The extract was obtained by filtering with Whatman filter paper and the filtrate freeze-dried in Armfield freeze-drier for 72 hours.

\section{Chemicals}

All the chemicals used were of analytical grade manufactured by Aldrich, BDH and Sigma Chemical Ltd., UK.

\section{Qualitative Phytochemical Screening}

Chemical tests were carried out on the aqueous extracts to determine the presence or absence of tannins, glycosides, resins, saponins, phlobatanins, flavonoids, sterols, phenols, carbohydrates, alkaloids and terpenoids using standard procedures as described by Trease \& Evans [40], Sofowora [38] and Harbone [15].

\section{E. Determination of in vitro Antioxidant Activity of Aqueous Extracts of Anacardium occidentale leaves and nuts}

1. Determination of Total Antioxidant Capacity of Aqueous Extract of Anacardium occidentale leaves and nuts

The method described by Prieto et al. was used [31]. An aliquot of $0.1 \mathrm{~mL}$ sample solution containing a reducing species was combined with $1 \mathrm{~mL}$ of reagent solution $(0.6 \mathrm{M}$ sulphuric acid, $28 \mathrm{mM}$ sodium phosphate and $4 \mathrm{mM}$ Ammonium molybdate) in a test tube. The tubes were incubated in a water bath at $95{ }^{\circ} \mathrm{C}$ for 90 minutes. After the samples were cooled to room temperature, the absorbance of the aqueous solution was measured at $695 \mathrm{~nm}$ against a blank, which contained $1 \mathrm{~mL}$ reagent solution and $1.1 \mathrm{~mL}$ $80 \%$ methanol and incubated under the same conditions as the sample. The concentration of standard ascorbic acid used was $100 \mu \mathrm{g} / \mathrm{mL}$. The antioxidant activity of the sample was measured as ascorbic acid equivalent (AAE).

2. Ferric Reducing Antioxidant Property Assay (FRAP) of Aqueous Extract of Anacardium occidentale leaves and nuts

The method of Benzie and Strain (1999) was used. 300 $\mathrm{mmol} / \mathrm{L}$ acetate buffer of $\mathrm{pH} \mathrm{3.6,} 10 \mathrm{mmol} / \mathrm{L} \mathrm{2,} \mathrm{4,} \mathrm{6-tri-(2-}$

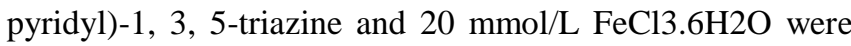
mixed together in the ratio 10: 1: 1 respectively, to give the working FRAP reagent. A $50 \mu \mathrm{L}$ aliquot of the sample extract at $1 \mathrm{mg} / \mathrm{mL}$ was added to $1 \mathrm{~mL}$ of FRAP reagent in a semi-micro plastic cuvette. Absorbance measurement was taken at $593 \mathrm{~nm}$ exactly 10 minutes after mixing using 
$50 \mathrm{~mL}$ of water as reference.

In standardizing, $50 \mu \mathrm{L}$ of the standard (FeSO4.7H2O, 1 $\mathrm{mmol} / \mathrm{L})$ was added to $1 \mathrm{~mL}$ of FRAP reagent. All absorbance were taken at room temperature with samples protected from direct sunlight.

3. DPPH Free Radical Scavenging Assay of Aqueous Extracts of Anacardium occidentale leaves and nuts

The method proposed and described by Blois (1958) was used to determine the hydrogen radical scavenging properties of the extracts using the stable radical DPPH (2, 2-Diphenyl-1-picrylhydrazyl hydrate). $1 \mathrm{~mL}$ of $0.3 \mathrm{mM}$ DPPH in methanol was added to $1 \mathrm{~mL}$ of varying concentrations $\quad(0.1, \quad 0.05, \quad 0.0025, \quad 0.0125, \quad 0.00625$, $0.003125 \mathrm{~g} / \mathrm{mL}$ ) of the sample extract and allowed to react. The mixture was thoroughly mixed and incubated in a dark cupboard for 30 minutes after which the absorbance was measured at $517 \mathrm{~nm}$ against a DPPH negative control containing only $1 \mathrm{~mL}$ of methanol in place of the sample. Distilled water was used as a blank. Ascorbic acid was used as standard.

4. Determination of Concentration of Total Phenols in aqueous extracts of Anacardium occidentale leaves and nuts

The total phenolic content was determined using the method described by Singleton and Rossi [37] using FolinCiocalteu's phenol reagent. $0.9 \mathrm{~mL}$ of distilled water was added to $0.1 \mathrm{~mL}$ of $1 \mathrm{mg} / \mathrm{mL}$ of the extract. Then $0.2 \mathrm{~mL}$ of Folin-Ciocalteu's phenol reagent was added and reacting mixture was vortexed. After 5 minutes, $1 \mathrm{~mL}$ of $7 \%(\mathrm{w} / \mathrm{w})$ $\mathrm{Na} 2 \mathrm{CO} 3$ solution was added to the mixture. The solution was then diluted to $2.5 \mathrm{~mL}$ and then incubated for 90 minutes at room temperature. The absorbance of the resulting product formed at $750 \mathrm{~nm}$ was then read against a negative control containing $1 \mathrm{~mL}$ of methanol in place of the sample. Reading was compared to that of the standard Gallic acid equivalent (GAE) of sample, after preparing a calibration curve. Distilled water was used as a blank.

5. Determination of Flavonoids Concentration in aqueous extracts of Anacardium occidentale leaves and nuts

The method of Boham and Kocipal-Abyazam [6] was used to determine the flavonoid concentration. About $0.25 \mathrm{~g}$ of the sample was extracted repeatedly with $100 \mathrm{~mL}$ of $80 \%$ aqueous methanol at room temperature. The whole solution was filtered through Whatman filter paper no. 42(125 mm). The filtrate was later transferred into a crucible and evaporated to dryness on a water bath and weighed to a constant weight.

6. Nitric Oxide (NO) Scavenging Assay of Aqueous Extract of Anacardium occidentale leaves and nuts

The method of Garrat [12] was used. The reaction mixture contained $10 \mathrm{mM}$ sodium nitroprusside, phosphate buffered saline ( $\mathrm{pH}$ 7.4) and various concentrations (0$70 \mu \mathrm{g} / \mathrm{mL}$ ) of the test solution in a final volume of $3 \mathrm{~mL}$. After incubation for 150 minutes at $25{ }^{\circ} \mathrm{C}, 1 \mathrm{~mL}$ sulphanilamide $(0.33 \%$ in $20 \%$ glacial acetic acid $)$ was added to $0.5 \mathrm{~mL}$ of the incubated solution and allowed to stand for 5 minutes. Then $1 \mathrm{~mL}$ of naphthylethylenediamine dihydrochloride (NED) $(0.1 \% \mathrm{w} / \mathrm{v})$ was added and the mixture incubated for 30 minutes at $25{ }^{\circ} \mathrm{C}$. The pink chromophore generated during diazotization of nitrite ions with sulphanilamide and subsequent coupling with NED was measured spectrophotometrically at $540 \mathrm{~nm}$ against a blank sample. All tests were performed in triplicates. Ascorbic acid was used as a standard.

7. Determination of Metal Chelating Activity of Aqueous Extracts of Anacardium occidentale leaves and nuts

The chelating of ferrous ions is estimated using the method of Dinis et al. [10]. Briefly, $0.1 \mathrm{~mL}$ of the extract was added to $0.5 \mathrm{~mL}$ of $0.2 \mathrm{mM}$ ferrous chloride solution. The reaction was initiated by the addition of $0.2 \mathrm{~mL}$ of ferrozine $(5 \mathrm{mM})$ and incubated at room temperature for 10 minutes and then the absorbance was measured at $562 \mathrm{~nm}$. Ethylene di-amine tetra acetic acid (EDTA) was used as the standard.

\section{F. Statistical Analysis}

All values were expressed as the mean of five determinations \pm S.E.M.

\section{RESULTS}

\section{A. Phyttochemical screening of extracts}

Phytochemical screening of the aqueous extracts of leaves and nuts of Anacardium occidentale revealed the presence of resins, flavonoids, phenols, carbohydrates, alkaloids and terpenoids. In addition, the aqueous extract of leaves showed the presence of tannins, saponins, phlobatanins and sterols (Table 1). However, glycosides were not detected in any of the samples tested.

TABLE 1: RESULTS FOR THE PHYTOCHEMICALS IN AQUEOUS EXTRACTS OF

\begin{tabular}{ccc}
\multicolumn{3}{c}{ ANACARDIUM OCCIDENTALE LEAVES AND NUTS } \\
\hline Phytochemicals & Leaf & Nut \\
\hline Tannins & + & - \\
Glycosides & - & - \\
Resins & + & + \\
Saponins & + & - \\
Phlobatanins & + & - \\
Flavonoids & + & + \\
Sterols & + & - \\
Phenols & + & + \\
Carbohydrates & + & + \\
Alkaloids & + & + \\
Terpenoids & + & + \\
\hline
\end{tabular}

+ Present; - Absent.

\section{B. In vitro antioxidant activity (of extracts)}

Table 2 revealed that both the aqueous extract of leaves and nuts of Anacardium occidentale exhibited remarkable in vitro antioxidant activity on the basis of the various parameters studied. However, the aqueous extract of the leaf was found to exhibit greater antioxidant activity with respect to $\mathrm{DPPH}$, NO scavenging and metal chelating activity because of the lower IC50 values obtained in these parameters. 
TABLE 2: RESULTS OF THE IN VITRO ANTIOXIDANT ACTIVITIES OF AQUEOUS EXTRACTS OF ANACARDIUM OCCIDENTALE LEAVES AND NUTS

\begin{tabular}{|c|c|c|c|c|c|c|c|}
\hline & \multicolumn{7}{|c|}{ PARAMETERS } \\
\hline \multirow[t]{2}{*}{ EXTRACT TYPE } & $\begin{array}{c}\text { Total } \\
\text { Antioxidant } \\
\text { Capacity (TAC) }\end{array}$ & $\begin{array}{l}\text { Ferric reducing } \\
\text { antioxidant } \\
\text { (FRAP) }\end{array}$ & $\begin{array}{l}\text { DPPH free } \\
\quad \text { radical } \\
\text { Scavenging }\end{array}$ & $\begin{array}{l}\text { Total Phenol } \\
\text { (GAE) }\end{array}$ & $\begin{array}{l}\text { Flavonoids } \\
\text { (GAE) }\end{array}$ & $\begin{array}{c}\text { Metal } \\
\text { Chelating }\end{array}$ & Nitric oxide \\
\hline & $\begin{array}{l}\text { Ascorbic Acid } \\
\text { Equivalent }\end{array}$ & \multicolumn{6}{|c|}{$\mathrm{IC}_{50}$ Values $(\mu \mathrm{g} / \mathrm{mL})$} \\
\hline Leaf & $36.77 \pm 1.11$ & $1.71 \pm 0.10$ & $1.01 \pm 0.07$ & $4.04 \pm 1.70$ & $3.91 \pm 0.10$ & $0.99 \pm 0.11$ & $0.21 \pm 0.01$ \\
\hline \multirow[t]{2}{*}{ Nut } & $34.85 \pm 0.27$ & $1.37 \pm 0.02$ & $4.65 \pm 0.09$ & $2.64 \pm 0.09$ & $2.54 \pm 0.14$ & $3.54 \pm 0.05$ & $8.65 \pm 0.09$ \\
\hline & & & Standards & & & & \\
\hline Ascorbic acid & - & - & $0.60 \pm 0.07$ & - & - & - & $0.20 \pm 0.01$ \\
\hline
\end{tabular}

Ethylene diamine tetra

acetic acid (EDTA)

$0.02 \pm 2.56 \mathrm{E} 05$

Values are means of five determinations + S.E.M

\section{DISCUSSION}

In this study, the result is similar to the one obtained by Jaiswal et al. [19], however, terpenoids, resins and carbohydrates were not investigated in the previous research. The presence of some of these metabolites suggests that the plant might be of medicinal importance [36]. Presence of these secondary metabolites may contribute to its antioxidant and pharmacological potentials. The knowledge of the chemical constituents of plants is desirable because such information will be valuable for synthesis of complex chemical substances and to screen for biological activities [24]. The phenols and flavanoids are widely distributed secondary metabolites in plants having anti-oxidant activity and wide range of biological activities such as anti-apoptosis, anti-aging, anti-carcinogen, antiinflammation, anti-atherosclerosis, cardiovascular protection and improvement of endothelial function, as well as inhibition of angiogenesis and cell proliferation activities [33].

Specifically the presence of phenolic compounds provides pharmacological activities like; anti-cancer [21], [26], antioxidant [21], [30], anti-microbial [17], [35], wound-healing [29] and anti-inflammatory [30], that may suggest an association to the specie here investigated.

\section{CONCLUSION}

Aqueous extract of the leaves of Anacardium occidentale contained tannins, resin, saponins, phlobatanins, flavonoids, steroids, phenols, carbohydrates, alkaloids and terpenoids. On the other hand, the aqueous extract of the plant's nuts contained resin, flavonoids, phenols, carbohydrates, alkaloids and terpenoids. However, none of the extracts contained glycosides. Furthermore, both extracts exhibited remarkable in vitro antioxidant activities with respect to the various parameters studied.

\section{REFERENCES}

[1] Anderson, G. D. (2004): Phytochemicals. Dynamic Chiropractic, 2(1), $1-2$.

[2] Adom, K. K. \& Liu, R. H. (2002): Antioxidant Activity of Grains. Journal of Agricultural and Food Chemistry, 50, 6182-6187.

[3] Benzie, F. F. \& Strain, J. J. (1999): Ferric Reducing/ Antioxidant Power Assay: Direct Measure of Total antioxidant Activity of
Biological Fluids and Modified Version for Simultaneous Measurement of Total Antioxidant Power and Ascorbic Acid Concentration. Methods in Enzymology, 299, 15-23.

[4] Block, G., Patterson, B. \& Subar, A. (1992): Fruit, vegetables, and cancer prevention: a review of the epidemiological evidence. Nutrition and Cancer-An International Journal, 18(1), 1-29.

[5] Blois, M. S. (1958): Antioxidant determination by the use of a stable free radical. Nature, 181, $1199-1200$.

[6] Boham, B. A. \& Kocipal-Abyazam, R. (1994): Flavonoids and Condensed Tannins from Leaves of Hawaiian Vaccinium vaticulatum and V. calycinium. Pacific Science; 48, $458-463$.

[7] Breinholt, V. (1999): Desirable versus harmful levels of intake of flavonoids and phenolic acids. Natural Antioxidants and Anticarcinogens in Nutrition, Health and Disease. Eds J. Kumpulainen and J.E. Salonen. The Royal Society of Chemistry, Cambridge. 37, 190-197.

[8] Chandrasekara, N. \& Shahidi, F. (2011): Effect of Roasting on Phenolic Content and Antioxidant Activities of Whole Cashew Nuts, Kernels, and Testa. Journal of Agricultural and Food Chemistry, 59, 5006-5014.

[9] Christen, Y. (2000): Oxidative stress and Alzheimer's disease. American Journal of Clinical Nutrition, 71, 621S-629S.

[10] Dinis, T. C. P., Maideira, V. M. C. \& Almeida, L. M. (1994): Actions of phenolic derivatives (Aceto aminophan, salycilate and 5aminosalycilate) as inhibitors of membrane lipid peroxidation and as peroxyl radical scavengers. Archives of Biochemistry and Biophysics. 315, 161-169.

[11] Duthie G. G., Duthie S. J. \& Kyle J. A. M. (2000). Plant polyphenols in cancer and heart disease: Implications as nutritional antioxidants, Nutrition Research Reviews, 13, 79-106.

[12] Garratt, D. C. (1964): The Quantitative Analysis of Drugs, Springer Boston, USA, pp. 62-67.

[13] Gokhan, Z., Abdurrahman, A., Gokalp, O. G., Yavuz S. C. \& Evren, Y. (2011): Antioxidant Properties of Methanolic Extract and Fatty acid Composition of Centaurea urvillei DC. Subsp. Hayekiana Wagenitz. Records of Natural Products, 5, 123-132.

[14] Hall, C. A. \& Cuppet, S. L. (1997): Activities of Natural antioxidants. In: Aruoma, O. I. and Cuppet, S. L. (Eds.), Antioxidant Methodology in vivo and in vitro Concepts. AOCS Press, Champaign, II, pp. 2-20.

[15] Harborne, J. B. (1983): Phytochemical Methods. A Guide To Modern Techniques Of Plant Analysis. 3rd Edn., Chapman and Hall Publishing, London, United Kingdom, p. 67.

[16] He, Z., Fu, M. \& Mao, L. (2011): Total phenolic and condensed tannin and antioxidant activity of four Caryaspecies from China. African Journal of Biotechnology, 10(51), 10472-10477.

[17] Hendra, R., Ahmad, S., Sukari, A., Shukor M.Y \& Oskoueian, E (2011): Flavonoid Analysis and Antimicrobial Activity of Various Parts of Phaleria Macrocarpa (Scheff.)Boerl Fruit. International Journal of Molecular Sciences, 12, 3422-3431.

[18] Hu, F. B. (2003): Plant-based foods and prevention of cardiovascular disease: an overview. American Journal of Clinical Nutrition, 78, 544S-551S.

[19] Jaiswal, Y. S., Tatke, P. A., Satish, Y.G. \& Ashok, V. (2010): Antioxidant Activity of Various Extracts of Leaves of Anacardium occidentale (Cashew). Research Journal of Pharmaceutical, Biological and Chemical Sciences, 1(4): 113.

[20] Kaur, C. \& Kapoor, H. C. (2001): Antioxidant in fruits and vegetables - the millennium's health. International Journal of Food Science and Technology, 36, 703-725. 
[21] Khacha-Ananda S., Tragoolpua K., Chantawannakul P \& Tragoolpua Y. (2013): Antioxidant and Anti-Cancer Cell Proliferation Activity of Propolis Extracts From Two Extraction Methods. Asian Pacific Journal of Cancer Prevention, 14, 6991-6995.

[22] Knekt, P., Kumpulainen, J., Jarvinen, R., Rissanen, H., Heliovaara, M., Reunanen, A., Hakulinen, T., \& Aromaa, A. (2002): Flavonoid intake and risk of chronic diseases. American Journal of Clinical Nutrition, 76, 560-568.

[23] Kris-Etherton, P. M., Hecker, K. D., Bonanome, A., Coval, S. M., Binkoski, A. E., Hilpert, K. F., Griel, A. E., \& Etherton, T. D. (2002): Bioactive compounds in foods: their role in the prevention of cardiovascular disease and cancer. American Journal of Medicine, $113,71 \mathrm{~S}-88 \mathrm{~S}$

[24] Kumari, M. (2003): Phytochemical screening and antioxidant activity of in vitro grown plants Clitoria ternatea L Using DPPH assay. Asian Journal of Pharmaceutical and Clinical Research, 6(2), 38-42.

[25] Larson, R. A (1988): The antioxidants of higher plants. Phytochemistry, 27, 969-978.

[26] Lin, Y., Shi, R.., Wang, X. \& Shen, H. M. (2008): Luteolin, A Flavonoid with Potential for Cancer Prevention and Therapy. Current Cancer Drug Target, 8(7), 634-646.

[27] Liu, R. H. (2003): Health benefits of fruit and vegetables are from additive and synergistic combinations of phytochemicals. American Journal of Clinical Nutrition, 78, 517S-520S.

[28] Narendra, V., Mukul T. \& Narayan, P. G. (2010): Antioxidant Potential of Psidium Guajava Linn. International Journal Pharmacy and Technology Research, 2, 417-419.

[29] Nayak, B. S.\& Pinto, P. L. M. (2006). Catharanthus roseus Flower Extract has Wound-Healing Activity in Sprague Dawley Rats. BMC Complement Alternative Medicine, 6, 41.

[30] Pourmorad F., Hosseinimehr S.J and Shahabimajd N. (2006) Antioxidant Activity, Phenol and Flavonoid Content of Some Selected Iranian Medicinal Plants. African Journal of Biotechnology, 5(11), 1142-1145.

[31] Prieto, P., Pineda, M. \& Aguilar, M. (1999): Spectrophotometric quantitation of antioxidant capacity through the formation of a Phosphomolybdenum Complex: Specific application to the determination of vitamin E. Analytical Biochemistry, 269, 337-341.

[32] Raghavendra, H. Lakshmanashetty, Y. B., Nagaraj, M. G. H \& Vadlapudi, K. (2010): In vitro Antioxidant Activity of Vitex negundo L. Leaf Extracts. Chiang mai Journal of Sciences, 37,489-497.

[33] Rice-Evans, C., Miller, N. \& Paganga, G. (1996): Structureantioxidant activity relationships of flavonoids and phenolic acids Free Radical Biology and Medicine, 21(3), 417.

[34] Rumit, S., Heena, K., Rajal, S. \& Naveen, S. (2010): In vitro Antioxidant Activity of Roots of Tephrosia Purpurea Linn. International Journal of Pharmacy and Pharmaceutical Sciences, 2, 30-33.

[35] Sengul, M., Yildiz, H., Gungor, N., Cetin, B., Eser, Z. \& Ercisli, S. (2009): Total Phenolic Content, Antioxidant and Antimicrobial Activities of Some Medicinal Plants. Pakistan Journal of Pharmaceutical Sciences, 22(1), 102-106.

[36] Shobana, G., Keerthana, K., Dr., Agnel A. J., Edwina, A. \& Sherley, F. (2015): In vitro antioxidant potentials of aqueous extract of Anacardium occidentale 1. World Journal of Pharmacy And Pharmaceutical Sciences, 5(1), 1458-1467.

[37] Singleton, V. L. \& Rossi, J. A., Jr. (1965): Colorimetry of total phenolics with phosphomolybdic- phosphotungstic acid reagents. American Journal of Enology and Viticulture,16, 144-158.

[38] Sofowora, A. (1989): Screening for Bioactive Agents. In: Medicinal Plants And Traditional Medicine In Africa, 2nd Ed., Spectrum Books Limited, Ibadan, Nigeria, pp. 134-156.

[39] Tiwari P., Kumar B., Kaur M., Kaur G. and Kaur K. (2011). Phytochemical screening and extraction: A review. Internationale Pharmaceutica Sciencia, 1(1), 98-106.

[40] Trease, G. E. \& Evans, W. C (1985). Pharmacognosy (11edn). English Language, The Book Society, Bailliere Tindall, Britain, pp. 45-50. 